\title{
The Water Stability Prediction Model of AC-25 Asphalt Mixture
}

\author{
Zhao-hui Sun*1 ,De-ying $\mathrm{Yu}^{2}$,Tie-bin Wang ${ }^{3}$,Guang-qiang Zhu ${ }^{1}$ \\ 1.The Traffic Engineering School of Shenyang Jianzhu University, China \\ 2.Shenyang Highway Administration Bureau \\ 3.Liaoning Provincial Traffic Engineering Quality and Safety Supervision Bureau, China
}

\begin{abstract}
Keywords: Water Stability, Prediction Model, Asphalt Mixture.
\end{abstract}
\begin{abstract}
AC-25 asphalt mixture are designed by referencing the orthogonal design method, the freeze-thaw cycle rutting test are carried out, the related model of the fractal dimension and the water stability evaluation index including freeze-thaw cycle dynamic stability ratio is established by using fractal theory. The water stability of AC-25 asphalt mixture can be predicted according to the gradation designed. This can reduce the test workload and offer the reference for engineering design.
\end{abstract}

\section{Introduction}

The correlation analysis can be carried out between the fractal dimension and the water stability.In this paper,we analyze the correlation between the fractal dimension and the water stability evaluation index of asphalt mixture, and establish the correlation model.

\section{The Raw Material Performance Test}

Liaohe petroleum asphalt grade A No.90, which is widely used in the northeast of China and the basic performance test results are shown in Table 1.

Table 1 Matrix asphalt technical index

\begin{tabular}{llll}
\hline Detection index & Unit & Test value & Specification requirements \\
\hline Penetration $\left(25^{\circ} \mathrm{C} 、 100 \mathrm{~g} 、 5 \mathrm{~s}\right)$ & $0.1 \mathrm{~mm}$ & 86.3 & $80-100$ \\
Ductility $\left(15^{\circ} \mathrm{C}\right)$ & $\mathrm{cm}$ & $>100$ & $\geq 50$ \\
Softening Point $(\mathrm{R} \& \mathrm{~B})$ & ${ }^{\circ} \mathrm{C}$ & 45.9 & $\geq 45$ \\
\hline
\end{tabular}

The coarse and fine aggregate of AC-25 mixture use limestone gravel produced by Liaoyang Xiaotun victory quarry. The basic performance test results are shown in table 2. 【3】

\section{Water Stability Test}

Water damage is particularly serious just at the beginning of winter and early spring season in the Northeast area of China. Therefore, it is very important to study the water stability of asphalt mixture in the Northeast of China. The water stability of asphalt mixture is evaluated by the method of freezing and thawing splitting test in the JTG E20-2011" Standard Test Methods of Bitumen and Bituminous Mixtures for Highway Engineering", The traditional Marshall hammer compaction test method is used to make the test piece in this method. It can not simulate the driving compaction; the larger size of the aggregate according with the quality requirements of the road is easy to be broken under the standard compaction conditions, the test data is discrete, and there is no direct connection with the performance of the road. Aiming at the shortage of current test method and the characteristics of the Northeast region, In this paper, a new method is put forward to simulate the stress state of asphalt mixture in the actual pavement. That is to say, the wheel rutting test under the 
condition of freezing and thawing cycle can better simulate the water stability of asphalt mixture in the Northeast of China.【5】

The dynamic stability ratio of asphalt mixture was proposed to evaluate the water stability of it. The dynamic stability ratio is defined as the ratio of the dynamic stability of the specimen after freezing thawing cycles and the dynamic stability of non freezing and thawing cycles. As is shown in the formula (1). There is currently no corresponding technical standards in specification, combining with the climatic zoning of the Northeast area belonged to, 0.85 is recommended as the standard value of dynamic stability ratio which is evaluation index of freeze-thaw cycle rutting test. Which requires the dynamic stability ratio DSR is more than or equal to $85 \%$.Test results are shown in table 4.

$$
\mathrm{DSR}=\frac{D S_{d r}}{D S_{0}}
$$

DSR — dynamic stability ratio;

$D S_{d r}$ — the dynamic stability of the specimen after freezing and thawing cycles (times $/ \mathrm{mm}$ ); $D S_{0}$ _the dynamic stability of non freezing and thawing cycles (times/mm).

Table 2 Technical index of limestone coarse aggregate

\begin{tabular}{|c|c|c|c|c|c|c|c|c|}
\hline Material specification & $(\mathrm{mm})$ & $\begin{array}{l}26.5-31 \\
5\end{array}$ & $19-26.5$ & $16-19$ & $13.2-16$ & & $9.5-13.2$ & $\begin{array}{l}4.75-9 . \\
5\end{array}$ \\
\hline Technical index & $\begin{array}{l}\text { Standard } \\
\text { value }\end{array}$ & Test value & & & & & & \\
\hline Crushing value $(\%)$ & $\leq 24$ & 15 & & & & & & \\
\hline $\begin{array}{l}\text { Apparent relative } \\
\text { density }\left(\mathrm{T} / \mathrm{m}^{3}\right)\end{array}$ & $\geq 2.5$ & 2.729 & 2.726 & 2.73 & 2.718 & & 2.729 & 2.732 \\
\hline $\begin{array}{l}\text { Water absorption rate } \\
(\%)\end{array}$ & $\leq 2.0$ & 0.12 & 1.18 & 0.26 & 0.28 & & 0.38 & 0.62 \\
\hline $\begin{array}{l}\text { Adhesion with asphalt } \\
\text { (Grade) }\end{array}$ & $\geq 4$ & 4 & & & & & & \\
\hline Consistency $(\%)$ & $\leq 8$ & 8 & & & & & & \\
\hline $\begin{array}{l}\text { Content of needle and } \\
\text { sheet granular }(\%)\end{array}$ & $\leq 12$ & 12 & & & & & & \\
\hline $\begin{array}{l}<0.075 \text { Particle content } \\
(\%)\end{array}$ & $\leq 1$ & 0.3 & & 0.3 & 0.3 & 0.3 & 0 . & 3 \\
\hline
\end{tabular}

Grade A No.90 road petroleum asphalt and limestone were tested in accordance with the requirements of the road usage.

\section{Water Stability Model}

The rutting test results of meeting the above water stability requirements in Northeast China and the corresponding fractal dimension are summarized in Table 3. 
Table 3 GAC-25 grading fractal dimension and dynamic stability ratio data

\begin{tabular}{ll|llll}
\hline $\begin{array}{l}\text { Gradation } \\
\text { types }\end{array}$ & $\begin{array}{l}\text { Dynamic stability } \\
\text { under 0.84MPa } \\
\text { DS (time } / \mathrm{mm})\end{array}$ & $\begin{array}{l}\text { Dynamic stability } \\
\text { ratio DSR }\end{array}$ & $\mathrm{D}$ & $\mathrm{D}_{\mathrm{c}}$ & $\mathrm{D}_{\mathrm{f}}$ \\
\hline AC-25-4 & 678 & 0.86 & 2.4495 & 2.3906 & 2.4877 \\
$\mathrm{AC}-25-12$ & 800 & 0.88 & 2.4917 & 2.5823 & 2.4256 \\
$\mathrm{AC}-25-15$ & 722 & 0.83 & 2.6117 & 2.3046 & 2.5689 \\
$\mathrm{AC}-25-17$ & 1104 & 0.83 & 2.5973 & 2.5915 & 2.5581 \\
$\mathrm{AC}-25-18$ & 719 & 0.82 & 2.5607 & 2.5098 & 2.5809 \\
$\mathrm{AC}-25-20$ & 671 & 0.88 & 2.4641 & 2.3147 & 2.3781 \\
\hline
\end{tabular}

The AC-25 mixture which aggregate gradation number is 4, 12, 15, 17, 18 and 20 meet simultaneously the requirements of high temperature and water stability.

As can be seen from table 3, the fractal dimension range of meeting the requirement of dynamic stability ratio is $\mathrm{D}=[2.4495,2.6117], \mathrm{Dc}=[2.3046,2.5915], \mathrm{Df}=[2.3781,2.5809]$

There is a correlation between the water stability performance of asphalt mixture and fractal dimension. First of all, three element linear regression is analyzed between the fractal dimension D、 Dc、Df and the dynamic stability ratio DSR, the three element linear regression model of dynamic stability ratio and fractal dimension is established. As can be seen in formula (2).

$$
\mathrm{DSR}=1.650-0.048 \mathrm{D}+0.011 \mathrm{D}_{\mathrm{c}}-0.283 \mathrm{D}_{\mathrm{f}}
$$

The regression coefficient $\mathrm{R} 2=0.959$

This can be shown that the three element linear regression model can be established between dynamic stability ratio and fractal dimension, and the regression coefficient is higher, so there are the correlation between dynamic stability ratio and the fractal dimension, the correlation analysis is done by data in Table 3, the correlation analysis results are shown in Table 4.

Table 4 The correlation of dynamic stability ratio and fractal dimension for AC-25 mixture

\begin{tabular}{l|llll}
\hline & DSR & $\mathrm{D}$ & $\mathrm{D}_{\mathrm{c}}$ & $\mathrm{D}_{\mathrm{f}}$ \\
\hline $\mathrm{DSR}$ & 1.000 & -0.835 & -0.138 & -0.975 \\
$\mathrm{D}$ & -0.835 & 1.000 & 0.179 & 0.815 \\
$\mathrm{D}_{\mathrm{c}}$ & -0.138 & 0.179 & 1.000 & 0.192 \\
$\mathrm{D}_{\mathrm{f}}$ & -0.975 & 0.815 & 0.192 & 1.000 \\
\hline
\end{tabular}

It can be seen from table 4, dynamic stability ratio DSR and three fractal parameters D, Dc, Df showed negative correlation characteristics. The correlation between the fractal dimension and DSR ordered from the big to small is Df, $>\mathrm{D}>\mathrm{DC}$ The correlation between DSR and Df is higher, but the correlation between DSR and the coarse aggregate fractal dimension DC is relatively lower. So the influence of gradation fractal dimension on water stability is relatively large, the correlation model between the fractal dimension and the dynamic stability ratio can be established. The related model of dynamic stability ratio DSR and D is shown in formula (3).

$$
\mathrm{DSR}=1.629-0.312 \mathrm{Df}
$$

The regression coefficient $\mathrm{R} 2=0.951$; 
As can be seen from the analysis, the correlation between dynamic stability ratio and fractal dimension $\mathrm{D}$ is relatively larger. The correlation model of dynamic stability ratio and fractal dimensions D is established. As is shown in formula (4)

$$
\mathrm{DSR}=1.661-0.321 \mathrm{D}
$$

The regression coefficient $\mathrm{R} 2=0.697$;

Similarly, a correlation model between dynamic stability ratio and gradation fractal dimension D, fine aggregate fractal dimension Df can be established. As is shown in formula (5).

$$
\mathrm{DSR}=1.668-0.046 \mathrm{D}-0.280 \mathrm{Df}
$$

The regression coefficient $\mathrm{R} 2=0.956$.

\section{Model Selection}

The correlation model of dynamic stability ratio and fractal dimension is established. The summary is listed in Table 5. It can be seen that from table 5, the regression coefficients of model 1 and 4 are higher, and the model 1 and 4 are recommended to be used as the water stability prediction model.

Table 5 Prediction model of dynamic stability ratio

\begin{tabular}{llcl}
\hline No. & \multicolumn{1}{c}{ Model expression } & $\begin{array}{c}\text { Regression } \\
\text { coefficient } \\
\mathrm{R}^{2}\end{array}$ & \multicolumn{1}{c}{ Characteristics } \\
\hline 1 & $\mathrm{DSR}=1.650-0.048 \mathrm{D}+0.011 \mathrm{D}_{\mathrm{c}}-0.283 \mathrm{D}_{\mathrm{f}}$ & 0.959 & $\begin{array}{l}\text { The regression coefficient } \\
\text { is higher }\end{array}$ \\
2 & $\mathrm{DSR}=1.629-0.312 \mathrm{D}_{\mathrm{f}}$ & 0.951 & $\begin{array}{l}\text { The regression coefficient } \\
\text { is relatively lower }\end{array}$ \\
3 & $\mathrm{DSR}=1.661-0.321 \mathrm{D}$ & 0.697 & $\begin{array}{l}\text { The regression coefficient } \\
\text { is lower } \\
\text { The regression coefficient } \\
\text { is higher }\end{array}$ \\
\hline & $\mathrm{DSR}=1.668-0.046 \mathrm{D}-0.280 \mathrm{D}_{\mathrm{f}}$ & 0.956 & \\
\hline
\end{tabular}

\section{Conclusions}

By the results of the above experiments and the model, the prediction model of the water stability is $\mathrm{DSR}=1.650-0.048 \mathrm{D}+0.011 \mathrm{D}_{\mathrm{c}}-0.283 \mathrm{D}_{\mathrm{f}}$ or $\mathrm{DSR}=1.668-0.046 \mathrm{D}-0.280 \mathrm{D}_{\mathrm{f}}$ these models are used to predict the water stability of AC-25 mixture, it can reduce the amount of testing, improve the working efficiency, and can be used for engineering design.

\section{Acknowledgement}

This research was financially supported by the Natural Science Foundation of China (51178278)

\section{References}

[1] Occupation Standard of the People's Republic of China., JTG E20-2011 "Standard Test Methods of Bitumen and Bituminous Mixtures for Highway Engineering" [S]

[2]Highway Science Research Institute, Ministry of Communications JTG F40-2004 "Technical Specifications for Construction of Highway Asphalt Pavements" [S] 
[3] Occupation Standard of the People's Republic of China, JTG E42-2005 "Test Methods of Aggregate for Highway Engineering”, [S]

[4]Nukunya,B., R.Roque,M.Tia,B. Birgisson. Evaluation of VMA and other Volumetric Properties as Criteria for the Design and Acceptance of Superpave Mixtures[J].Journal of the Association of Asphalt Paving Technologists, 79(2002) 38-69

[5]Zhao-Hui SUN, Tie-Bin WANG, Ze-Feng WU and Zhi-Song WANG, Research on the Evaluation Method of Water Stability for Large Size aggregate Particle Asphalt Mixture Applied Mechanics and Materials Vol. 692 (2014) 497-500

[6]Al-Swailmi S., Evaluation of Water Damage of Asphalt Concrete Mixtures

Using the Environmental Conditioning System (ECS). Proceedings, (2012). 